\title{
A Significant Population Signal in Iranian Temperature Records
}

\author{
Shouraseni Sen Roy, ${ }^{1}$ Mohammad Sadegh Keikhosravi Kiany, ${ }^{2}$ and Robert C. Balling ${ }^{3}$ \\ ${ }^{1}$ Department of Geography and Regional Studies, University of Miami, Coral Gables, FL, USA \\ ${ }^{2}$ Faculty of Geographical Sciences and Planning, University of Isfahan, Isfahan, Iran \\ ${ }^{3}$ School of Geographical Sciences and Urban Planning, Arizona State University, Tempe, AZ, USA
}

Correspondence should be addressed to Shouraseni Sen Roy; ssr@miami.edu

Received 28 March 2016; Accepted 11 August 2016

Academic Editor: Panagiotis Nastos

Copyright (C) 2016 Shouraseni Sen Roy et al. This is an open access article distributed under the Creative Commons Attribution License, which permits unrestricted use, distribution, and reproduction in any medium, provided the original work is properly cited.

\begin{abstract}
We assembled daily maximum and minimum temperature records for 31 stations throughout Iran over the period 1961-2010. As with many other areas of the world, we found that both the maximum and minimum temperatures were increasing overall with the minimum temperatures increasing twice as fast as the maximum temperatures. We gathered population data for the stations near the beginning and end of the temperature records and found in all seasons and for both the maximum and minimum temperatures the magnitude of population growth positively influenced the temperature trends. However, unlike so many other studies, we found the strongest population growth signal in the winter for the maximum temperatures. We found evidence that this winter-season population-temperature signal is related snow cover. Our results illustrate that any number of processes are involved in explaining trends in historical maximum and minimum temperature records.
\end{abstract}

\section{Introduction}

According to the latest report of the Intergovernmental Panel on Climate Change (IPCC), it has been widely validated that the lower troposphere has experienced warming over the past 50 to 100 years, with substantial decadal and interannual variability. Specifically, the average global linear trends for combined land and ocean surface temperatures have increased by 0.85 [0.65 to 1.06$]^{\circ} \mathrm{C}$ between 1880 and 2012. In one of the first and most comprehensive studies at the global scale focusing on the spatial patterns of maximum, minimum, and diurnal temperature range (DTR), Vose et al. [1] showed a declining trend in DTR. This declining trend in DTR was attributed to the more rapid rate of increase in minimum temperatures when compared to maximum temperatures. This was further validated by a recent study by Donat et al. [2] involving the analysis of HADEX2 dataset, who found significant decreasing trends in DTR in more than half of the land areas; only $10 \%$ of the land area showed significant increases in DTR since 1951.

Some of the physical processes attributed to the declining rates in DTR include the effect of clouds, along with the damping effect of precipitation and soil moisture, which can cause a 25-50\% decrease in DTR compared to clear sky days [3]. Furthermore, the results of empirical analyses suggest the intensification of the hydrologic cycle, such as the increase in trends in frequency and intensity of tropical storms, floods, and droughts. This has also resulted in the amplification of the warming effect of water vapor in the atmosphere [4]. However, snow cover during winter season diminished the influence of changes in solar radiation and soil moisture in the mid latitudes [5]. Furthermore, a recent study by Revadekar et al. [6] showed an increasing trend in DTR for high altitude stations located in South Asia, while a decreasing trend was observed in the low altitude stations. The increasing trends in DTR in high altitude locations were mainly attributed to local level processes.

In this context, one of the main driving forces for the increasing trends in land surface temperatures is the function of land use land cover change (LULCC) and urban heat island (UHI) related processes. The role of urbanization, with more than half of global population living in urban areas, has been identified as one of the most important factors for higher temperatures. It is important to take into consideration the 
effect of UHI which is greater for places that have undergone recent urbanization compared to those places that have been urban for an extended period of time. Thus the effect of UHI on the long-term temperatures varies based on the location and population history of an urban area.

While a large literature has evolved over the past century showing that urbanization creates localized warming, especially at night, the extent to which this effect impacts longterm trends in temperature at regional, hemispheric, or even global scales is a matter of some debate. In their most recent assessment, IPCC Working Group I scientists [7, page 37] report in the technical summary that "it is unlikely that any uncorrected urban heat island effects and land use change effects have raised the estimated centennial globally averaged land surface air temperature trends by more than $10 \%$ of the reported trend. This is an average value; in some regions that have rapidly developed urban heat island and land use change impacts on regional trends may be substantially larger." Later in the report, they review the evidence that the urban effect is generally much larger during the nighttime and morning hours compared to warmer periods of the day when maximum temperatures are recorded.

Indeed, an assessment of articles published in the most recent five years supports this finding. For example, Saaroni and Ziv [8] examined the urban heat island effect in the arid city of Beer Sheba, Israel, and found, despite its odd topographic setting, the city was influencing night temperatures far more than day temperatures, particularly in the summer season. Elagib [9] investigated daily temperatures in and around Khartoum, Sudan, and found significant urban induced warming in the minimum temperatures and cooling in the maximum temperatures in all seasons. Similarly, Singh et al. [10] found that minimum temperatures were rising faster than maximum temperatures during the 1988 to 2007 period in Dehradun, India, during which urbanization and industrialization increased substantially after the city became the capital of the newly formed state of Uttarakhand in 2000. Several recent papers from China have quantified the portion of warming that can be attributed to urbanization as opposed to regional or even global warming signals. Wang and Ge [11] examined stations in China that had undergone intense urbanization and found that local effects accounted for $41 \%$ of the observed warming from 1980 to 2005. Similarly, He et al. [12] examined the records of 69 stations in China and concluded that $44.1 \%$ of the warming signal over the past three decades was urbanization induced. Assessment of the IPCC reports along with the results of dozens of recent papers reinforces the conclusion that urbanization induces a warming signal with the effect being much greater on the minimum temperatures compared to maximum temperatures.

In this investigation, we focus on minimum and maximum daily temperatures collected throughout Iran over the period 1961-2010. We identify annual and seasonal trends in maximum and minimum temperatures and compare the trends to population growth that has occurred in the vicinity of the weather stations. Our focus on Iran is particularly interesting given the large population increase in Iran, particularly the growth of the country in urbanized areas [13]. The results of our study are significant in view of recent studies
TABLE 1: List of weather stations along with the metadata.

\begin{tabular}{lccccc}
\hline Number & Station & Longitude & Latitude & Height & WMO. N \\
\hline 1 & Abadan & 48.25 & 30.37 & 7 & 40831 \\
2 & Ahwaz & 48.67 & 31.33 & 12 & 40811 \\
3 & Anzali & 49.45 & 37.48 & -26 & 40718 \\
4 & Arak & 49.77 & 34.10 & 1708 & 40769 \\
5 & Babolsar & 52.65 & 36.72 & -21 & 40736 \\
6 & Bam & 58.35 & 29.10 & 1067 & 40854 \\
7 & Bandarabass & 56.37 & 27.22 & 10 & 40895 \\
8 & Birjand & 59.20 & 32.87 & 1491 & 40809 \\
9 & Bushehr & 50.82 & 28.97 & 20 & 40858 \\
10 & Esfahan & 51.67 & 32.62 & 1601 & 40800 \\
11 & Ghazvin & 50.05 & 36.25 & 1278 & 40731 \\
12 & Gorgan & 54.40 & 36.90 & 13 & 40738 \\
13 & Hamadan & 48.72 & 35.20 & 1850 & 40767 \\
14 & Kermanshah & 47.15 & 34.35 & 1420 & 40766 \\
15 & Khoy & 44.97 & 38.55 & 1180 & 40703 \\
16 & Mashhad & 59.63 & 36.27 & 990 & 40745 \\
17 & Oroomieh & 45.05 & 37.67 & 1312 & 40712 \\
18 & Ramsar & 50.67 & 36.90 & -20 & 40732 \\
19 & Rasht & 49.62 & 37.32 & 37 & 40719 \\
20 & Sabzevar & 57.65 & 36.20 & 978 & 40743 \\
21 & Saghez & 46.27 & 36.25 & 1480 & 40727 \\
22 & Sanandaj & 47.00 & 35.33 & 1373 & 40747 \\
23 & Shahrekord & 50.85 & 32.28 & 2061 & 40798 \\
24 & Shahroud & 54.95 & 36.42 & 1380 & 40739 \\
25 & Shiraz & 52.60 & 29.53 & 1488 & 40848 \\
26 & Tabriz & 46.28 & 38.08 & 1361 & 40706 \\
27 & Tehran & 51.32 & 35.68 & 1191 & 40754 \\
28 & Torbat Heydarieh & 59.22 & 35.27 & 1350 & 40762 \\
29 & Yazd & 54.28 & 31.90 & 1230 & 40821 \\
30 & Zahedan & 60.88 & 29.47 & 1369 & 40856 \\
\hline & Zanjan & 48.48 & 36.68 & 1663 & 40729 \\
\hline & & & & &
\end{tabular}

highlighting the increasing variability in long-term climate conditions such as higher incidences of droughts in certain regions of the country [14]. In addition, Iran's population has also seen significant changes as a result of varying population policies during different political periods.

\section{Temperature Data}

We obtained daily temperature data from the Islamic Republic of Iran Meteorological Organization (IRIMO). There are more than 150 synoptic weather stations in Iran but we had to limit our analyses to only 31 stations because of the shortness of the period and/or gaps in daily maximum and minimum temperature records of many of the stations (Table 1). Our selected weather stations covered all of the climatic regions of the country, and all stations have data spanning the entire period from 1961 to 2010. Among the stations used, nearly all of them have more than $99 \%$ of available days except for the stations at Saghez, Oroomieh, and Kermanshah. Figure 1 shows the distribution of stations used across the country 


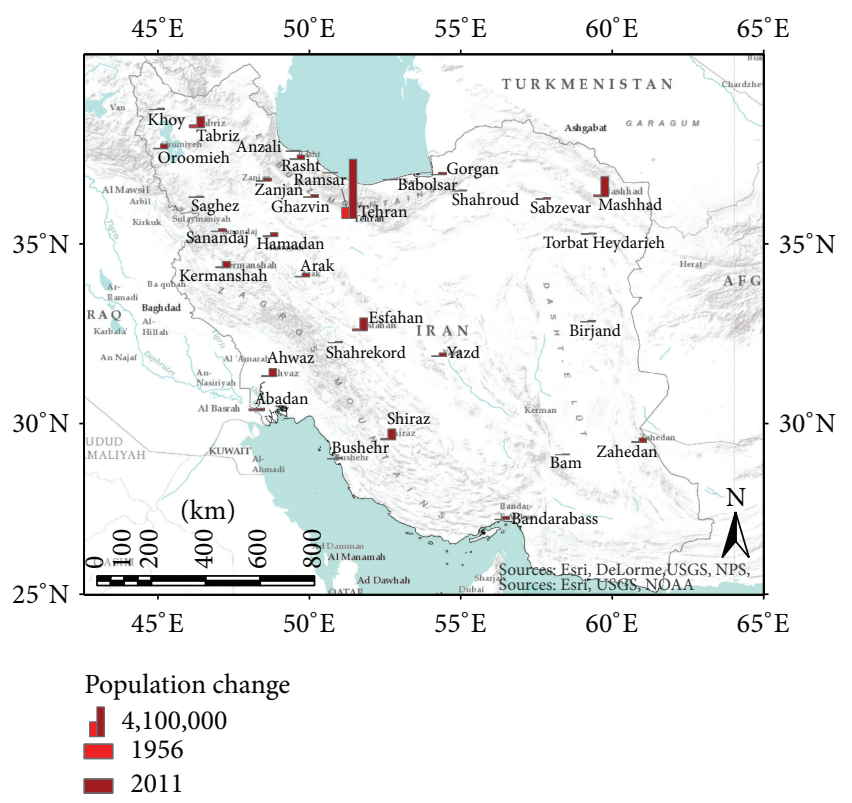

FIgURE 1: Distribution of the 31 stations throughout Iran used in this study.

along with change in population between 1956 and 2011. A nearest neighbor analysis was conducted to check for any form of clustering among the spatial distribution of stations across the study area. The Nearest Neighbor Index is expressed as the ratio of the observed mean distance to the expected mean distance. The expected distance is the average distance between neighbors in a hypothetical random distribution. If the index is less than 1 , the pattern exhibits clustering; if the index is greater than 1 , the pattern is dispersed or even uniform [15]. The nearest neighbor statistic for the network of stations used in the present study is 1.20, thus indicating no evidence of clustering for the network.

Iran, located in Southwest Asia, experiences a predominantly semiarid to arid climate. There are significant spatial and temporal variations in the long-term climate conditions across the region, with substantial variations in rainfall and a high propensity for drought $[16,17]$. For instance, in major cities such as Tehran, Mashhad, and Esfahan, which are also the leading population centers, drought like conditions have resulted in significant reduction in surface and ground water availability. Additionally, the annual average temperatures for the entire time period ranged between $9^{\circ} \mathrm{C}$ and $27^{\circ} \mathrm{C}$. The average maximum temperatures ranged between $16^{\circ} \mathrm{C}$ in Oroomieh in the north and $32.3^{\circ} \mathrm{C}$ in Abadan in the south central Iran. The average minimum temperatures ranged between $1.3^{\circ} \mathrm{C}$ in Saghez in the north and $21.78^{\circ} \mathrm{C}$ in Bandarabass in the south. In general the lower temperatures were clustered in the higher elevation regions of the Zagros Mountains.

\section{Population Data}

In a detailed study, Abbasi et al. [18] described the temporal changes in Iran's population over the years which coincided with three different political periods. As a result of better health care and population policies, Iran experienced major population growth in the 1970s and 1980s, which was followed by a relative decline in the rate of population growth. This population growth also led to increased rural to urban migration. Consequently, according to the national census report in 2011, about $71.2 \%$ of the total 75.2 million population of Iran live in cities. Among these cities, Tehran is considered to be an overpopulated city with 8.2 million people living there in the metropolitan area [19]. The importance of Iranian cities as centers of economic and cultural changes that have occurred since the Islamic revolution in 1979 has been highlighted in several studies [20, 21]. A study by Fanni [13] provided interesting insights into population growth in Iran from 1976 to 2002 and showed that the urban growth rate averaged $4.3 \%$ while the rural growth rate averaged $1.3 \%$ over that time period.

Therefore, in order to investigate the role of population increase in cities on temperature changes, population data were obtained from the official reports of the Statistical Centre of Iran for 1956 to 2011. The first population collection (census) was held in Iran in 1956 and after that, a population census was conducted on intervals of approximately 10 years. The latest population data available to us are from 2011. Historical population data were not available for the entire time period for two stations including Babolsar and Ramsar in the north, both of which are not major population centers. Therefore, the analyses conducted on the relationship between population growth and temperature trends were limited to 29 stations across the study area.

We found that the population increased at all of our 29 weather stations from 1956 to 2011 (Figure 1). The main population centers are located in the major cities of Tehran, Mashhad, and Esfahan. In terms of percentage increase between 1956 and 2011, the highest percentages were mainly located along the border in the east and north [22].

\section{Analyses and Results}

To begin our analyses of the trends in maximum and minimum temperatures across Iran, we determined the linear trend in ${ }^{\circ} \mathrm{C}$ decade ${ }^{-1}$ on the annual and seasonal basis. The seasonal classification used in the present study includes spring (March to May), summer (June to August), autumn (September to November), and winter (December to February). We conducted all analyses by season and found little variability in the minimum temperature trends across the four seasons (Figure 2). Trends for maximum temperatures were consistently less in all seasons compared to their minimum temperature counterparts but did show more interseasonal variability. The higher rate of increase in minimum temperatures is consistent with the results of a study by Tabari and Hosseinzadeh Talaee [23]. The spatial patterns of the trends in temperature patterns are shown in Figure 3. All stations experienced positive trends in both maximum and minimum temperatures at the seasonal scale. Overall, the trends in minimum temperatures were higher than the maximum temperatures. At the seasonal scale, the trends were usually higher during the winter and spring seasons for the maximum 


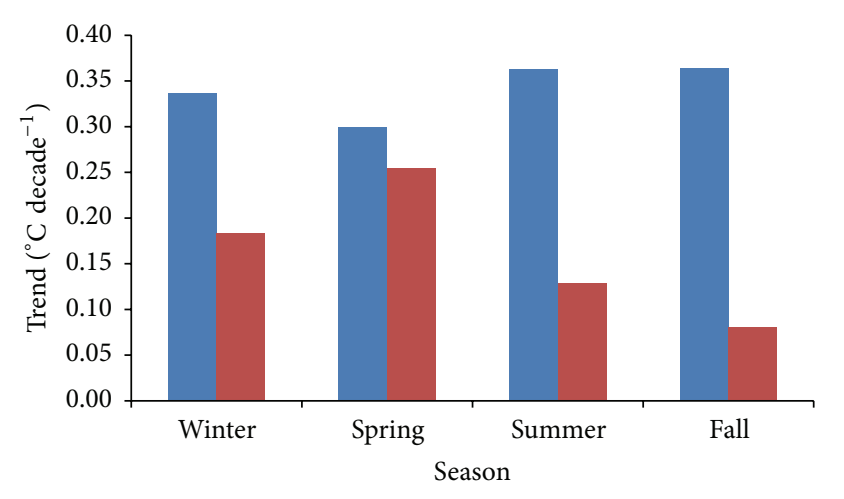

- Minimum

- Maximum

Figure 2: Seasonal trends $\left({ }^{\circ} \mathrm{C}\right.$ decade $\left.^{-1}\right)$ for maximum and minimum temperatures.

temperatures (Figure 3(a)) and during the summer and fall seasons for the minimum temperatures (Figure 3(b)). In the case of the maximum temperatures, higher trends were clustered in western Iran, over the Zagros Mountains, while the lower trends were observed in northern Iran. In the case of the minimum temperatures, the highest trends were observed in northeast Iran with lower trends located in the northwest.

We next tested the trend values for normality (a Gaussian distribution) across the 31-station network. The KolmogorovSmirnov one-sample test indicated that both spatial arrays had no significant $(p<0.05)$ deviations from the normal distribution. Furthermore, we computed the standardized coefficients of skewness, $z_{1}$, and kurtosis, $z_{2}$, as

$$
\begin{aligned}
& z_{1}=\frac{\left[\sum_{i=1}^{N}\left(x_{i}-\bar{X}\right)^{3} / N\right]\left[\sum_{i=1}^{N}\left(x_{i}-\bar{X}\right)^{2} / N\right]^{-3 / 2}}{(6 / N)^{1 / 2}}, \\
& z_{2} \\
& =\frac{\left\{\left[\sum_{i=1}^{N}\left(x_{i}-\bar{X}\right)^{4} / N\right]\left[\sum_{i=1}^{N}\left(x_{i}-\bar{X}\right)^{2} / N\right]^{-2}\right\}-3}{(24 / N)^{1 / 2}},
\end{aligned}
$$

where the resulting $z$ values were compared against a $t$ value deemed appropriate for a selected level of confidence (e.g., for $N=31, t=2.04$ for the 0.05 confidence level). Consistent with the Kolmogorov-Smirnov one-sample test, the standardized coefficients of skewness and kurtosis showed no significant deviations from normality in either the maximum or the minimum temperature trend values across the 31 stations (Table 2).

As seen in Table 2, the mean trend for the maximum temperatures was $0.186^{\circ} \mathrm{C}$ decade ${ }^{-1}$ while the mean trend for the minimum temperatures was $0.357^{\circ} \mathrm{C}$ decade $^{-1}$. We computed the difference between the two trends using Student's $t$-test for unequal variances. We found the $t$ value to be 2.592 which exceeds the 2.04 threshold for the 0.05 level of confidence. This leads us to conclude that minimum temperatures have increased nearly twice as fast as maximum temperatures in Iran, the difference is statistically significant, the diurnal
TABLE 2: Mean and standard deviations in temperature trends $\left({ }^{\circ} \mathrm{C}\right.$ decade $^{-1}$ ), normality statistics, and measure of spatial autocorrelation.

\begin{tabular}{lccccccc}
\hline Variable & Mean & Std. dev. & $N$ & K-S & $z_{1}$ & $z_{2}$ & Moran's I \\
\hline $\begin{array}{l}\text { Maximum } \\
\text { temp. }\end{array}$ & 0.186 & 0.185 & 31 & 0.121 & -1.150 & -0.362 & -0.015 \\
$\begin{array}{l}\text { Minimum } \\
\text { temp. }\end{array}$ & 0.357 & 0.319 & 31 & 0.136 & -0.764 & -0.821 & 0.047 \\
\hline
\end{tabular}

temperature range values across the country have declined, and average temperatures have increased. The results are consistent with the findings of Rahimzadeh et al. [24] based on 27 stations in Iran over a period beginning between 1951 and 1961 and ending in 2003.

We calculated Moran's $I$ as a measure of spatial autocorrelation for the maximum and minimum temperature trends. Spatial autocorrelation of a set of points measures whether or not points close to one another have similar values for some attribute. High, positive spatial autocorrelation indicates that points with similar characteristics are close to one another. The general form of the equation for the spatial autocorrelation coefficient, SAC, is

$$
\mathrm{SAC}=\frac{\sum_{i=1}^{n} \sum_{j=1}^{n} c_{i j} w_{i j}}{\sum_{i=1}^{n} \sum_{j=1}^{n} w_{i j}},
$$

where $c_{i j}$ represents the dissimilarity of attributes at points $i$ and $j, w_{i j}$ is the proximity of the location of points $i$ and $j$ set equal to $1 / d_{i j}^{2}$, where $d_{i j}$ is the distance between points, $x_{i}$ is the value of an attribute of point $i$, and $n$ is the number of points in the distribution. In the case of Moran's $I, c_{i j}=$ $\left(x_{i}-\bar{x}\right)\left(x_{j}-\bar{x}\right)$, and the value will be positive for similar and negative for dissimilar points. Finally, SAC is divided by $s^{2}$ which is the spatial variance of $x$ to produce Moran's $I$ value.

The autocorrelation values (Table 2) were low and not statistically significant indicating a near randomness in the trend values across the network. We conducted a trendsurface analysis on the temperature trend values and found no significant relationship with the latitude or longitude of the 31 stations. These findings lead to the conclusion that there is no strong underlying spatial pattern in trends of either the maximum or the minimum temperatures across Iran.

Next we analyzed any relationship that might exist between the annual trend values and the change in population that occurred at the stations between 1956 and 2011. The analyses were complicated by the lack of normality in the change in population variable driven by the large population increase of over 6.6 million people in Tehran. Neglecting that fact, the Pearson product-moment correlation coefficient between population increase and maximum temperature trends was $0.279(p=0.143)$ and $0.362(p=0.054)$ for the minimum temperatures. If Tehran is eliminated from the analyses, the correlation coefficients are $0.451(p=0.016)$ and 0.365 ( $p=0.056)$, respectively, for the maximum and minimum trend values. Finally, we calculated the Spearman rank-order correlation coefficients (Spearman's $\rho$ ) between the trend values and the change in population; these coefficients are 


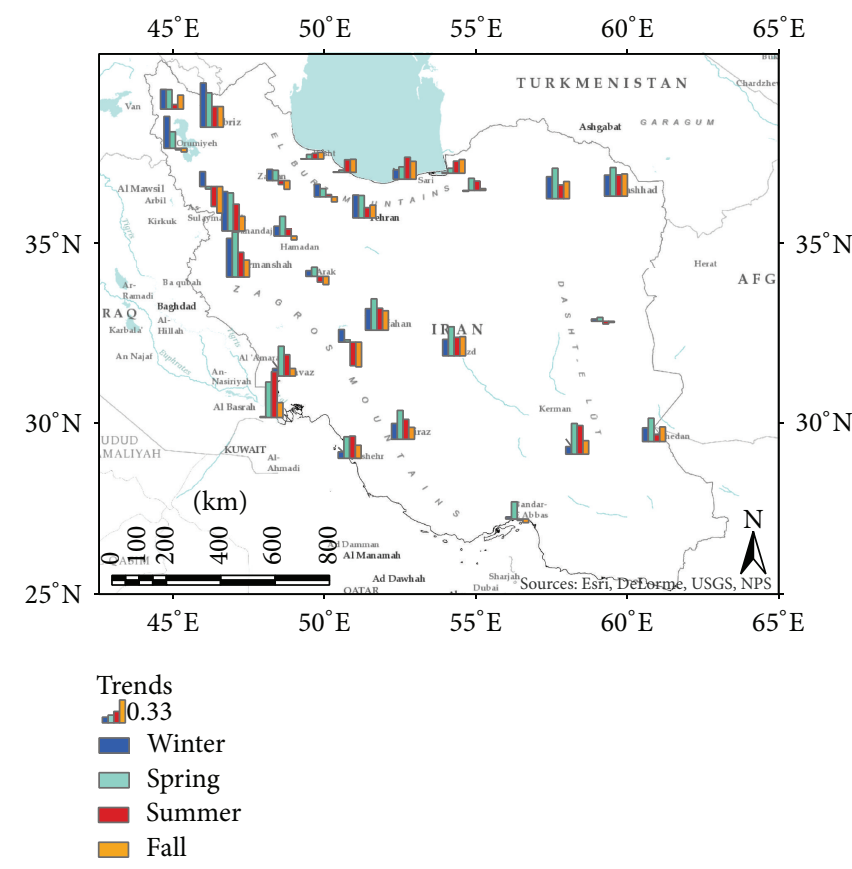

(a)

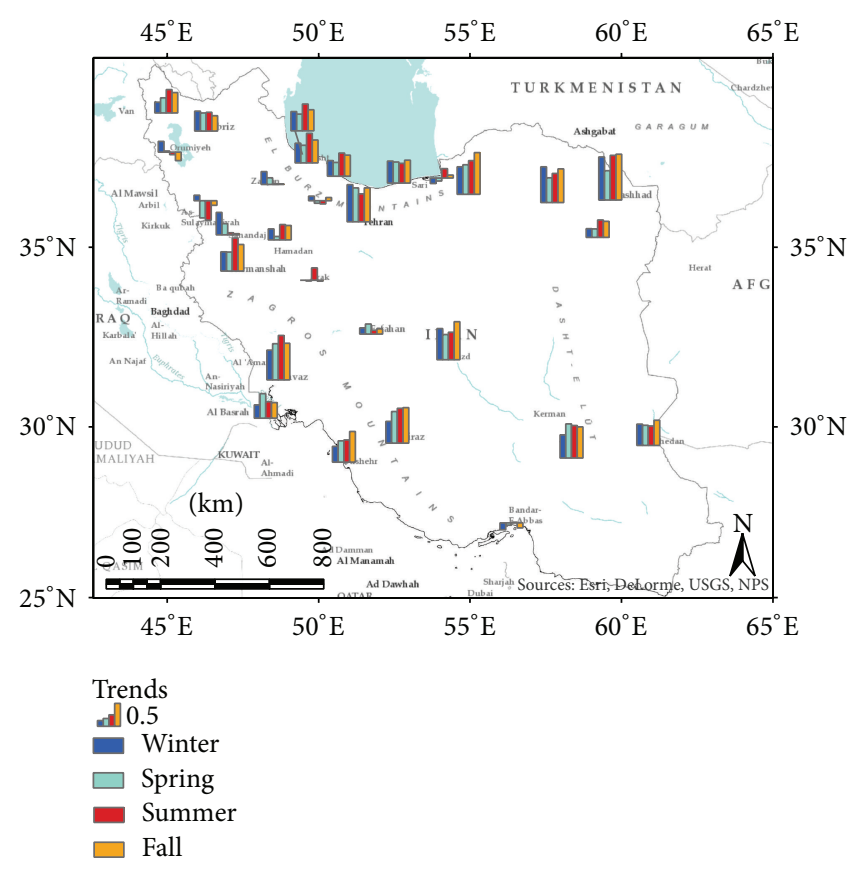

(b)

FIGURE 3: Spatial patterns of station level trends in seasonal temperatures from 1961 to 2010. (a) Maximum temperatures. (b) Minimum temperatures.

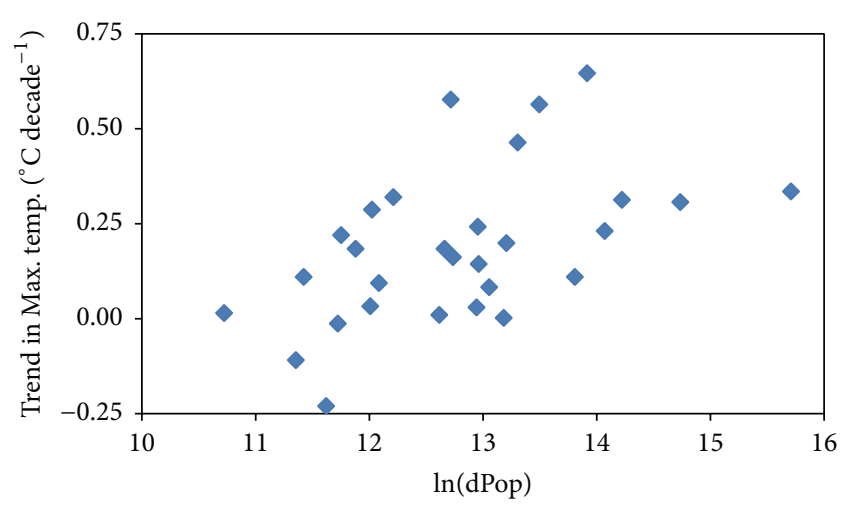

FIGURE 4: Winter-season trend in maximum temperature $\left({ }^{\circ} \mathrm{C}\right.$ decade $^{-1}$ ) and the natural log of the change in population from 1956 to 2011 .

not based on any assumption that the data have normal distributions. The coefficients are $0.431(p=0.030)$ and 0.280 ( $p=0.141)$, respectively, for the maximum and minimum temperature trends. These results are based on a relatively low number of stations $(N=29)$ and yet, a highly statistically significant signal is confirmed that temperature trends in Iran are influenced by population growth in and around the weather stations.

Additionally, when we examined the data on a seasonal basis, the Spearman rank-order correlation coefficients show the strongest relationship ( $\rho=0.579, p=0.001$ ) with the change in population variable appeared with the wintertime maximum temperature trends (Table 3, Figure 4). To further
TABLE 3: Spearman rank-order correlation coefficients $(\rho)$ between temperature trends and change of population at 29 stations.

\begin{tabular}{lcccc}
\hline Season & $\begin{array}{c}\text { Spearman's } \rho \\
\text { Maximum } \\
\text { temp. }\end{array}$ & $\begin{array}{c}p \\
\text { Maximum } \\
\text { temp. }\end{array}$ & $\begin{array}{c}\text { Spearman's } \rho \\
\text { Minimum } \\
\text { temp. }\end{array}$ & $\begin{array}{c}p \\
\text { Minimum } \\
\text { temp. }\end{array}$ \\
\hline Winter & 0.579 & 0.001 & 0.300 & 0.113 \\
Spring & 0.417 & 0.024 & 0.239 & 0.212 \\
Summer & 0.250 & 0.191 & 0.269 & 0.162 \\
Fall & 0.354 & 0.059 & 0.210 & 0.275 \\
\hline
\end{tabular}

explore this unusual finding, we obtained monthly snowsleet days for the 31 stations across the country from the IRIMO. The time period of the monthly snow-sleet days for the stations used covers from 1961 to 2010. There were no snow-sleet days at some of the stations such as Abadan, Ahwaz, Bushehr, and Bandarabass, but there were snow-sleet days observed in many of other stations in Iran (Figure 5). The spatial patterns of the trends in the average number of snow-sleet days across Iraq are mapped in Figure 6; the map suggests that there are no significant trends in snow-sleet days in any part of the study area.

A multiple regression showed that both the natural log of population growth and the number of snow-sleet days were both positively and significantly $(p<0.05)$ related to the trends in winter-season maximum temperature; $38.7 \%$ of the spatial variance in the winter maximum temperature trends was explained by the two predictors. The Pearson productmoment correlation coefficient between population growth and the number of snow-sleet days was 0.05 indicating little 


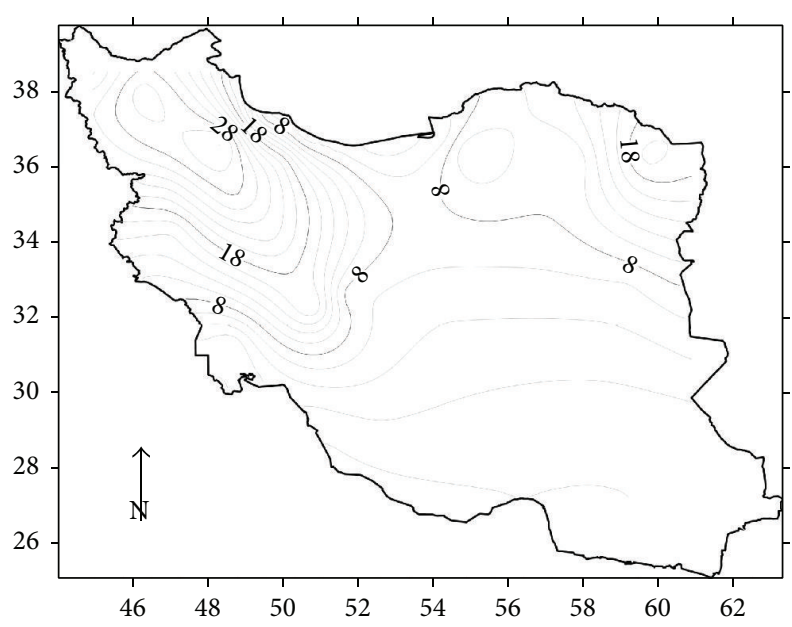

Figure 5: Map of average number of snow-sleet days across Iran.

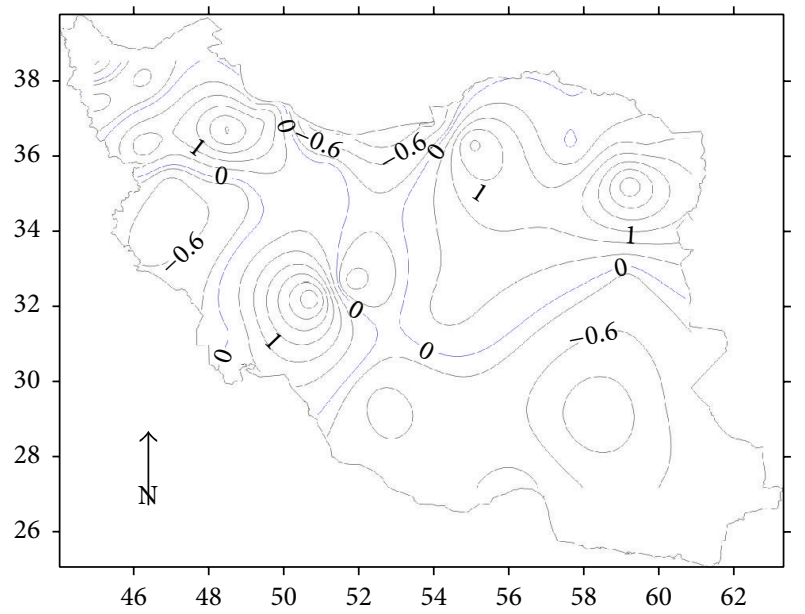

FIGURE 6: Map of trends in average number of snow-sleet days across Iran, calculated as Mann-Kendall scores that would need to be below -2.18 or above 2.18 to be significant at the 0.05 level of confidence.

shared variance between the two predictors. These findings are supported by Baker et al. [25] who found that variations in snow cover strongly influence maximum temperatures during the winter season.

\section{Conclusions}

We examined temperature records from Iran over the period 1961-2010 and arrived at three fundamental conclusions:

(1) Across the entire country, maximum and minimum temperatures have increased significantly over the past five decades with the minimum temperatures increasing nearly twice as fast as the maximum temperatures. As with many other places in the world, the diurnal temperature range in Iran has decreased.

(2) We found strong evidence that population growth has influenced trends in maximum and minimum temperature across the country.
(3) Somewhat surprisingly, the strongest relationship between population growth and temperature trends appeared with the winter-season maximum temperatures. This suggested some feedback with snow cover, and indeed, we did find a significant relationship between trends in winter maximum temperature and the number of snow-sleet days.

Our findings add to a large body of knowledge on how temperatures may be responding to processes occurring from the global to local scales. Our research is the first effort focusing at the possible relationships that exist between population increase of the cities, urbanization, and temperature changes in Iran. The link to snow was an unexpected finding that may be investigated in other settings around the world.

\section{Competing Interests}

The authors declare that they have no competing interests.

\section{Acknowledgments}

The authors kindly thank the Islamic Republic of Iran Meteorological Organization for providing them with the temperature and snow-sleet data required for their study and the Statistical Centre of Iran for providing population data.

\section{References}

[1] R. S. Vose, D. R. Easterling, and B. Gleason, "Maximum and minimum temperature trends for the globe: an update through 2004," Geophysical Research Letters, vol. 32, no. 23, 2005.

[2] M. G. Donat, L. V. Alexander, H. Yang et al., "Updated analyses of temperature and precipitation extreme indices since the beginning of the twentieth century: the HadEX2 dataset," Journal of Geophysical Research Atmospheres, vol. 118, no. 5, pp. 2098-2118, 2013.

[3] A. Dai, K. E. Trenberth, and T. R. Karl, "Effects of clouds, soil moisture, precipitation, and water vapor on diurnal temperature range," Journal of Climate, vol. 12, no. 8, pp. 2451-2473, 1999.

[4] T. G. Huntington, "Evidence for intensification of the global water cycle: review and synthesis," Journal of Hydrology, vol. 319, no. 1-4, pp. 83-95, 2006.

[5] D. A. Stone and A. J. Weaver, "Factors contributing to diurnal temperature range trends in twentieth and twenty-first century simulations of the CCCma coupled model," Climate Dynamics, vol. 20, no. 5, pp. 435-445, 2003.

[6] J. V. Revadekar, S. Hameed, D. Collins et al., "Impact of altitude and latitude on changes in temperature extremes over South Asia during 1971-2000," International Journal of Climatology, vol. 33, no. 1, pp. 199-209, 2013.

[7] IPCC, Climate Change 2013: The Physical Science Basis. Intergovernmental Panel on Climate Change, Cambridge University Press, Cambridge, UK, 2013.

[8] H. Saaroni and B. Ziv, "Estimating the urban heat island contribution to urban and rural air temperature differences over complex terrain: application to an Arid city," Journal of Applied Meteorology and Climatology, vol. 49, no. 10, pp. 2159-2166, 2010.

[9] N. A. Elagib, "Evolution of urban heat island in Khartoum," International Journal of Climatology, vol. 31, no. 9, pp. 1377-1388, 2011. 
[10] O. Singh, P. Arya, and B. S. Chaudhary, "On rising temperature trends at Dehradun in Doon valley of Uttarakhand, India," Journal of Earth System Science, vol. 122, no. 3, pp. 613-622, 2013.

[11] F. Wang and Q. S. Ge, "Estimation of urbanization bias in observed surface temperature change in China from 1980 to 2009 using satellite land-use data," Chinese Science Bulletin, vol. 57, no. 14, pp. 1708-1715, 2012.

[12] Y. He, G. Jia, Y. Hu, and Z. Zhou, "Detecting urban warming signals in climate records," Advances in Atmospheric Sciences, vol. 30, no. 4, pp. 1143-1153, 2013.

[13] Z. Fanni, "Cities and urbanization in Iran after the Islamic revolution," Cities, vol. 23, no. 6, pp. 407-411, 2006.

[14] B. Ashraf, R. Yazdani, M. Mousavi-Baygi, and M. Bannayan, "Investigation of temporal and spatial climate variability and aridity of Iran," Theoretical and Applied Climatology, vol. 118, no. 1, pp. 35-46, 2014.

[15] P. J. Clark and F. C. Evans, "Distance to nearest neighbor as a measure of spatial relationships in populations," Ecology, vol. 35, no. 4, pp. 445-453, 1954.

[16] S. Sanjani, M. Bannayan, and M. Kamyabnejad, "Detection of recent climate change using daily temperature extremes in Khorasan Province, Iran," Climate Research, vol. 49, no. 3, pp. 247-254, 2011.

[17] M. Bannayan and S. Sanjani, "Weather conditions associated with irrigated crops in an arid and semi-arid environment," Agricultural and Forest Meteorology, vol. 151, no. 12, pp. 15891598, 2011.

[18] M. J. Abbasi, A. Mehryar, G. Jones, and P. McDonald, "Revolution, war and modernization: population policy and fertility change in Iran," Journal of Population Research, vol. 19, no. 1, pp. 25-46, 2002.

[19] S. E. Asgharpour, H. Zanjani, and G. Taleghani, "Impact of urbanization on population changes in metropolitan area of Tehran, Iran," in Proceedings of the 3rd International Geography Symposium (GEOMED '13), Antalya, Turkey, 2013.

[20] F. Hesamian and G. Eatemad, Urbanization in Iran, Ahgh Press, 1989.

[21] H. Shakoii, Urban Geography of Iran, Payam Noor University Press, 1992.

[22] M. Deghan, "Effects of drought on agriculture and ways to deal with it," Department of Technical and Policy, Core Technical Support Team, Department of Agriculture, 2010.

[23] H. Tabari and P. Hosseinzadeh Talaee, "Analysis of trends in temperature data in arid and semi-arid regions of Iran," Global and Planetary Change, vol. 79, no. 1-2, pp. 1-10, 2011.

[24] F. Rahimzadeh, A. Asgari, and E. Fattahi, "Variability of extreme temperature and precipitation in Iran during recent decades," International Journal of Climatology, vol. 29, no. 3, pp. 329-343, 2009.

[25] D. G. Baker, D. L. Ruschy, R. H. Skaggs, and D. B. Wall, "Air temperature and radiation depressions associated with a snow cover," Journal of Applied Meteorology, vol. 31, no. 3, pp. 247-254, 1992. 

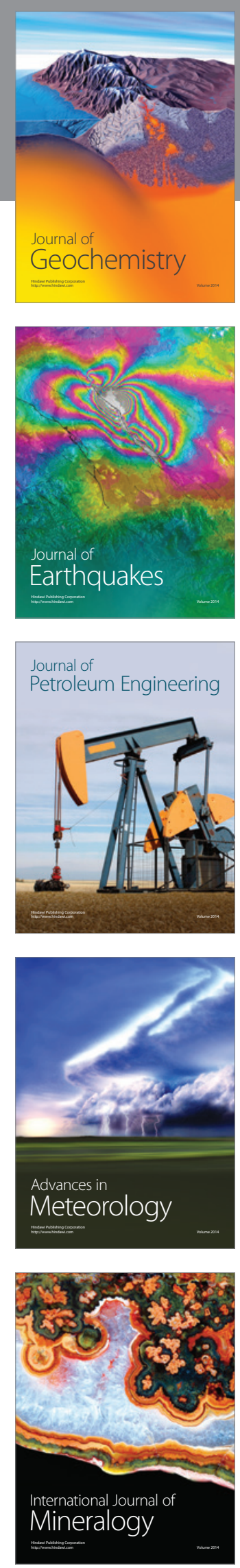
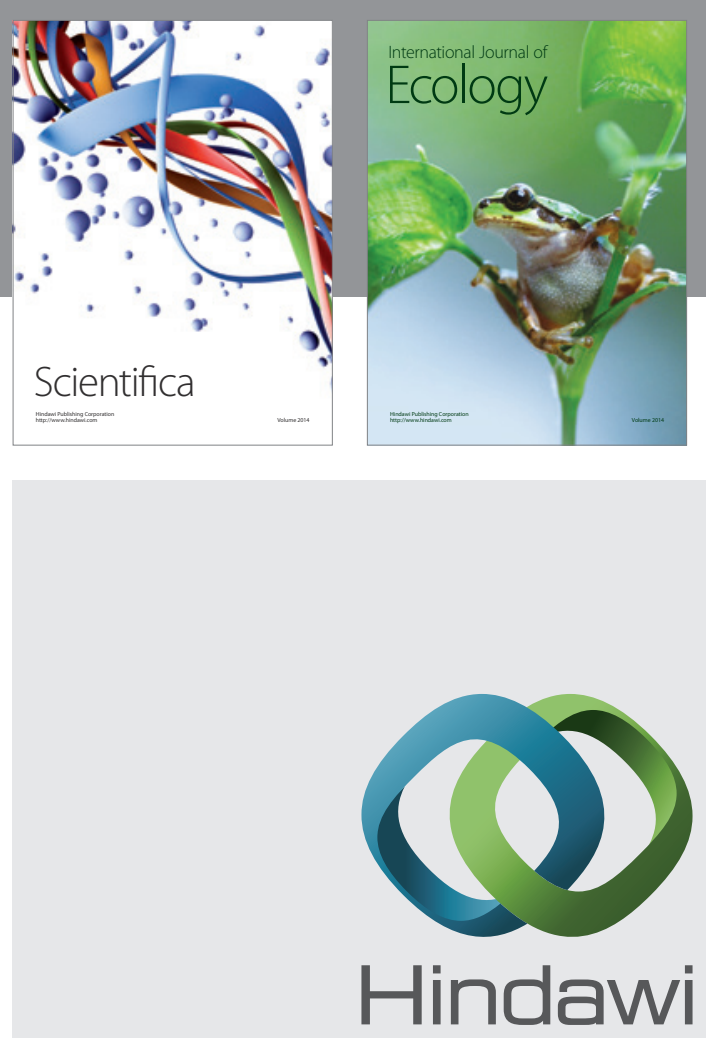

Submit your manuscripts at

http://www.hindawi.com
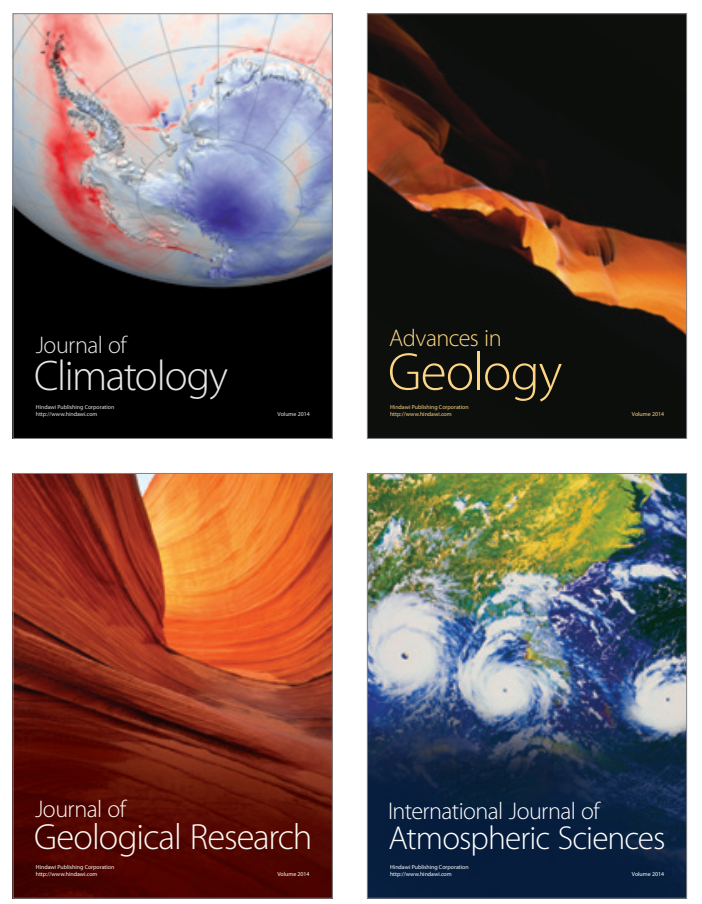

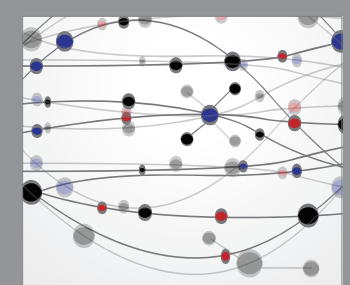

The Scientific

\section{World Journal}
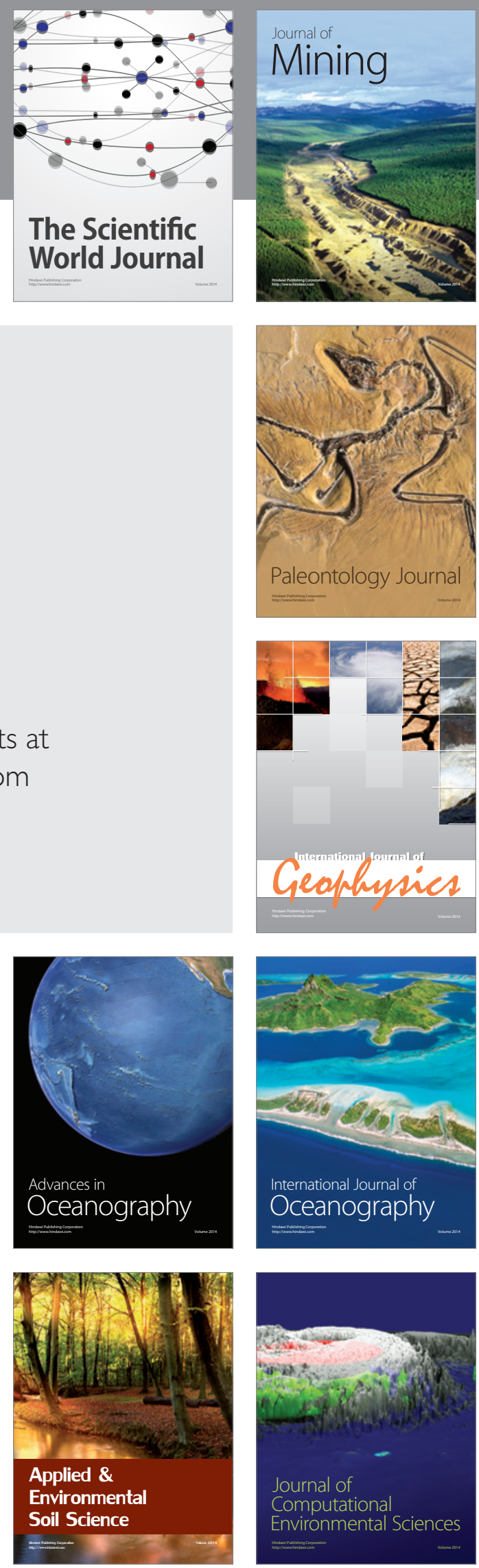